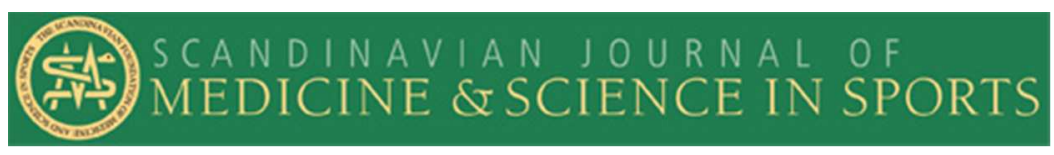

\title{
Longitudinal Development of Match-running Performance in Elite Male Youth Soccer Players
}

\begin{tabular}{|r|l|}
\hline Journal: & Scandinavian Journal of Medicine and Science in Sports \\
\hline Manuscript ID: & SJMSS-O-860-14.R3 \\
\hline Manuscript Type: & Original Article \\
\hline Date Submitted by the Author: & n/a \\
\hline Complete List of Authors: & $\begin{array}{l}\text { Saward, Chris; Nottingham Trent University, Sport, Health and } \\
\text { Performance Enhancement (SHAPE) Research Group, Department of Sport } \\
\text { Science } \\
\text { Morris, John; Nottingham Trent University, Sport, Health and Performance } \\
\text { Enhancement (SHAPE) Research Group, Department of Sport Science } \\
\text { Nevill, Mary; Nottingham Trent University, Sport, Health and Performance } \\
\text { Enhancement (SHAPE) Research Group, Department of Sport Science } \\
\text { Nevill, Alan; University of Wolverhampton, Faculty of Education, Health and } \\
\text { Wellbeing } \\
\text { Sunderland, Caroline; Nottingham Trent University, Sport, Health and } \\
\text { Performance Enhancement (SHAPE) Research Group, Department of Sport } \\
\text { Science }\end{array}$ \\
\hline Keywords: & \begin{tabular}{l} 
talent, time-motion analysis, association football \\
\hline
\end{tabular} \\
\hline
\end{tabular}


1

2

3

4

5

6

7

8

9

10

11

12

13

14

15

16

17

18

19

20

21

22

23

24

25

26

27

28

29

30

31

32

33

34

35

36

37

38

39

40

41

42

43

44

45

46

47

48

49

50

51

52

53

54

55

56

57

58

59

60
This article is original, has not already been published, has not been submitted for publication in other journals, and will not be submitted elsewhere until a final decision has been made by the Scandinavian Journal of Medicine \& Science in Sports. 
Longitudinal Development of Match-running Performance in Elite Male Youth Soccer Players

CHRIS SAWARD ${ }^{1}$, JOHN G. MORRIS ${ }^{1}$, MARY E. NEVILL ${ }^{1}$, ALAN M. NEVILL $^{2}$ and CAROLINE SUNDERLAND ${ }^{1}$

${ }^{1}$ Sport, Health and Performance Enhancement (SHAPE) Research Group, Department of Sport Science, School of Science and Technology, Nottingham Trent University, $U K$.

${ }^{2}$ Faculty of Education, Health and Wellbeing, University of Wolverhampton, UK.

Corresponding Author: Mr Chris Saward. Address: Nottingham Trent University,

Clifton Lane, Nottingham, UK, NG11 8NS. Tel: +44(0)1159418418. Email:

chris.saward@ntu.ac.uk

Running Head: Match-running Performance in Youth Soccer 
Abstract

This study longitudinally examined age-related changes in the match-running performance of retained and released elite youth soccer players aged 8-18 years. The effect of playing position on age-related changes was also considered. Across three seasons 263 elite youth soccer players were assessed in 1-29 competitive matches (988 player-matches). For each player-match, total distance and distances covered at age-group-specific speed zones (low-speed, high-speed, sprinting) were calculated using $1 \mathrm{~Hz}$ or $5 \mathrm{~Hz}$ GPS. Mixed modelling predicted that match-running performance developed non-linearly, with age-related changes best described with quadratic age terms. Modelling predicted that playing position significantly modified age-related changes $(p<0.05)$ and retained players covered significantly more low-speed distance compared to released players $(p<0.05)$, by $75 \pm 71 \mathrm{~m} \cdot \mathrm{h}^{-1}($ mean $\pm 95 \%$ CI $)($ effect size $\pm 95 \%$ CI: $0.35 \pm$ 0.34). Model intercepts randomly varied, indicating differences between players in match-running performance unexplained by age, playing position or status. These findings may assist experts in developing training programmes specific to the match-play demands of players of different ages and playing positions. Although retained players covered more low-speed distance than released players, further study of the actions comprising low-speed distance during match-play is warranted to better understand factors differentiating retained and released players. 


\section{Introduction}

The match-running performance of elite male senior soccer players has been extensively described (e.g. Di Salvo et al., 2007; Bradley et al., 2009; Carling, 2011). Indeed, a recent study of English male Premier League players showed that during a 90 minute match, mean \pm SD distance covered was $10714 \pm 991 \mathrm{~m}$, of which $2492 \pm$ $625 \mathrm{~m}$ was at high-speed $\left(>4 \mathrm{~m} \cdot \mathrm{s}^{-1}\right)$ (Bradley et al., 2009). Moreover, these playing characteristics have been shown to distinguish between players of differing standards, for example, Mohr et al. (2003) showed that top-class professional players performed more high-speed running $\left(>4.17 \mathrm{~m} \cdot \mathrm{s}^{-1}\right)$ and sprinting $\left(>8.33 \mathrm{~m} \cdot \mathrm{s}^{-1}\right)$ during match-play than moderate-ability professional players. However, to date very few studies have considered the match-running performance of elite youth soccer players, which is surprising considering the potential such information could have in providing insight into talent identification and development processes in soccer. Indeed, understanding age-related changes in the match-running performance of elite youth soccer players would have implications for the assessment of match performance, the design of effective training programmes, and the development of relevant physiological testing procedures (Carling et al., 2008). Moreover, examining match performance characteristics that discriminate more and less successful elite youth soccer players may aid the process of identifying players with the potential to become senior professionals (Waldron \& Murphy, 2013).

The findings of the limited number of studies that have considered the match-running performance of elite male youth soccer players suggest, through cross-sectional comparison of 8-10 years (Goto et al., 2013), 11-16 years (Harley et al., 2010), and 12-18 year old players (Pereira Da Silva et al., 2007; Buchheit et al., 2010; MendezVillanueva et al., 2013), that there is a general trend for total distance covered during 
match-play to increase with age. These total distances ranged from $4356 \pm 478 \mathrm{~m}$ in U9 players (Goto et al., 2013) to $8867 \pm 859 \mathrm{~m}$ in U18 players (Buchheit et al., 2010). However, match durations are shorter for younger players and so it is considered appropriate to normalise distances covered to match-time (Carling et al., 2008). When adjusted to match-time, differences between age groups in distance covered still exist but are less apparent, especially at older ages (Buchheit et al., 2010). Nevertheless, to confirm age-related changes in distance covered during match-play, studying a group of elite youth players across an age range that encapsulates an entire talent development programme is required.

The age-related changes in distance covered at various speeds by elite youth soccer players during match-play are less clear than changes in total distance covered. Buchheit et al. (2010) showed that when adjusted to match time, U18 players covered more sprinting distance $\left(>5.31 \mathrm{~m} \cdot \mathrm{s}^{-1}\right)$ compared to U13-U17 players. However, when mean 10 m flying peak speed of each specific age group was used to categorise speed zones only limited differences in high-speed distance covered per minute during match-play were evident in elite youth players aged U9-U10 (Goto et al., 2013) and U12-U16 (Harley et al., 2010). Conversely, Mendez-Villanueva et al. (2013) used individualised speed zones and showed that in the first half of match-play elite youth players aged U13 covered more distance at very high relative speeds compared to U15-U18 players. Thus, the age-related changes in distance covered at varying speeds during match-play of elite youth soccer players remain unclear and require further investigation, across a wider age range.

Another major shortcoming of research assessing age-related changes in matchrunning performance of elite youth players is that study designs have been crosssectional in nature, that is, comparisons made between different players in each age 
category (Strøyer et al., 2004; Pereira Da Silva et al., 2007; Buchheit et al., 2010; Goto et al., 2013; Mendez-Villanueva et al., 2013). Multiple observations of the same individuals are needed to allow changes within and differences between young players to be identified more accurately (Williams et al., 2011). The use of repeated measures multi-level statistical techniques to assess longitudinal changes in match-running performance characteristics would also support this type of study design (Brink et al.,2010).

Match-running performance of elite youth players is known to be influenced by playing position. In elite youth players aged 12-18 years, centre backs cover the least, and centre midfielders the most, total distance (Buchheit et al., 2010). Despite differences in speed zone definitions between studies, it appears that centre backs also cover the least, and wide midfielders and centre forwards the most, high-speed distance (Pereira Da Silva et al., 2007; Aslan et al., 2010; Buchheit et al., 2010; Mendez-Villanueva et al., 2013,). These differences suggest a mature tactical understanding of position-specific tasks (Buchheit et al., 2010). Whether these findings extend to younger elite youth players remains unclear.

There have been some attempts to differentiate between elite and sub-elite youth soccer players on the basis of match-running performance (Strøyer et al., 2004, Waldron \& Murphy, 2013). However, to date, only Goto et al. (2013) have examined the match-running performance of a group of highly selected, homogenous players, involved in elite talent development programmes, from a talent identification perspective. The authors examined 36 elite youth soccer players aged U9 and U10 and showed no differences between retained and released players in total distance covered per hour, but retained players completed more low-speed running distance compared to released players. The promising work of Goto et al. (2013) needs to be extended to 
provide insight into any differences between released and retained elite youth players across a wider age range.

The aim of the present study was to employ a longitudinal design to examine agerelated changes in match-running performance of retained and released elite male youth soccer players aged 8-18 years. A secondary aim was to examine how playing position affects the age-related changes in match-running performance of elite male youth soccer players age 8-18 years.

\section{Material and methods}

\section{Participants}

A total of 263 elite male youth soccer players aged 8-18 years, belonging to three professional academies participated in the study. The U9-U14 age groups averaged three 90 minute training sessions a week, the U15 and U16 age groups averaged four 90 minute training sessions a week and, the U17-U19 age groups averaged six 90 minute training sessions a week. Players participated in a competitive match once a week. The mean \pm SD age, height, and body mass of players within each age group are displayed in Table 1.

Ethical approval for the study was obtained from the Ethical Advisory Committees at Nottingham Trent University and Loughborough University. Prior to taking part in the study, players and parents or guardians were provided with a written and verbal summary outlining the purpose, procedures involved, possible risks and benefits, and the voluntary and confidential nature of the research. Written assent was obtained from players and written consent was obtained from parents or guardians. Prior to undertaking sprint tests, players went through a health screening process to identify any reasons that may prevent any players from taking part in the study. 


\section{INSERT TABLE 1 HERE}

Design

Across three soccer seasons from 2010/11 to 2012/13 (mean \pm SD duration range per player: $0.72 \pm 0.85$ years), the match-running performance of 263 elite youth soccer players was assessed in 1-29 competitive inter-academy matches (mean \pm SD number of matches per player: $3.77 \pm 4.46$ matches), resulting in a total of 988 player-matches. To evaluate match-running performance, total distance covered, and distance covered in low-speed ( $<45 \%$ age group mean peak flying speed), high-speed ( $\geq 45 \%$ age group mean peak flying speed), and sprinting ( $\geq 75 \%$ age group mean peak flying speed) zones were calculated for each player-match, using a GPS system. Distances were adjusted for match time to allow comparisons between ages. This repeated measures design allowed age-related changes in each match-running performance characteristic to be assessed. Playing position for each player-match was recorded to allow the effect of playing position on the age-related changes in match-running performance of elite youth players to be considered. At the end of the study the playing status of players was categorised as released or retained depending on whether they were signed to their academy on $1^{\text {st }}$ Feb 2014, resulting in 97 players being categorised as released and 166 players being categorised as retained. Differences between released and retained elite youth players in the age-related changes in match-running performance characteristics were then examined. 


\section{Experimental Procedures}

\section{Match configuration.}

The matches analysed were part of the regular series of inter-academy matches between Premier League academies during a season. The configuration of matches varied depending on age group. Indeed, U9 and U10 matches were small-sided games, that ranged from 5-a-side to 7-a-side and U11 matches ranged from 7-a-side to 11aside. These matches were formed of four periods, with total match duration between 60-80 minutes. For the U12 age group and older, matches were 11-a-side. The U12 and U13 matches were formed of three or four periods, with total match duration between 75-80 minutes. For the U14 age group and older, matches were formed of two periods, with total match duration between 80-90 minutes. Matches were played on pitches with dimensions in accordance with recommendations made by the Football Association (n.d.) for a given age group / match configuration. For example, U10 7 v 7 matches took place on pitches with dimensions of $\sim 35 \mathrm{~m} \mathrm{x} \sim 55 \mathrm{~m}$.

The playing position of each player was recorded for every match. Goal keepers were excluded from the analysis. Players were categorised as a centre back (CB), full back (FB) centre midfielder $(\mathrm{CM})$, wide midfielder (WM) or centre forward (CF). Players who changed position mid-match were categorised as multi positional (Multi). For small-sided games teams did not employ centre backs or wide midfielders.

\section{Match analysis.}

Each player's match-running performance was assessed using a $1 \mathrm{~Hz}$ or $5 \mathrm{~Hz}$ GPS system (GPSport, Australia). Both systems have been validated for use by team players (Macleod et al., 2009; Waldron et al., 2011). Possible differences between the 
two GPS systems in measuring distances were controlled for statistically by including the GPS sampling rate as a covariate during data analysis (Cummins et al., 2013). During match-play, each player wore a harness containing a GPS unit positioned between the shoulder blades. Post-match, each GPS unit was downloaded to a laptop computer and analysed using commercially available software (Team AMS, v 2.1). Total distance and distance covered within age specific speed zones were calculated (see below). All distances were adjusted to 60 minutes of match-play to allow for differences in match duration due to substitutions and match configurations. Players were only included for analysis if they had played at least half of a given match. For all data, mean $\pm \mathrm{SD}$ satellite coverage was $8.8 \pm 1.1$.

Distance covered by players during match-play was classified into different categories on the basis of age group sprint performance to provide more detailed information regarding speed of movement. Speed zones were normalised to age using the mean peak 10-20 m flying sprint speed of each age group (procedural details below). Player activity was classified into three speed zones: low-speed, high-speed and sprinting. The low-speed zone represented any distance covered at less than $45 \%$ of the age group mean peak 10-20 m flying speed and included standing, walking, jogging, and slow-running activity. The high-speed zone represented any distance covered at $45 \%$ or more of the age group mean peak 10-20 m flying speed and included cruising, fastrunning, and sprinting activity. The sprinting zone represented any distance covered at $75 \%$ or more of the age group mean peak 10-20 m flying speed and included sprinting activity (Table 2 ).

INSERT TABLE 2 HERE

Peak 10-20 m flying sprint speed. 
The 10-20 m flying sprint speed of 107 players from the study population, in addition to 161 other elite youth soccer players, was repeatedly assessed across five soccer seasons (2007 to 2011) resulting in 1,119 player-sprints for elite youth soccer players aged 8-18 years. Participants completed a $20 \mathrm{~m}$ sprint test with a split at $10 \mathrm{~m}$, on an indoor new-generation synthetic surface. Times were measured to the nearest $0.01 \mathrm{~s}$ using infrared photoelectric cells (Brower timing system, Utah, USA). Sprint tests were preceded by a familiarisation and standardised warm-up procedure. Three $20 \mathrm{~m}$ sprints were performed; each effort was separated by a 2-5 minute recovery period. The sprint with the shortest time between 10 and 20 m was used to calculate peak 10$20 \mathrm{~m}$ flying sprint speed for each player. The mean peak 10-20 m flying speed for each age group was calculated.

\section{Data Analysis}

Due to the hierarchical structure of the data, mixed modelling was used to predict the development with age of each match-running performance characteristic (MLwiN v 2.22, Bristol, U.K.). For each variable, a two-level hierarchical structure was defined with repeated measures (level 1) nested within players (level 2). Unlike traditional longitudinal data analysis techniques, such as the repeated measures ANOVA, mixed modelling does not require the same number of measurement occasions per individual. Moreover, the temporal spacing of measurements may vary between players (Rasbash et al., 2009). Hence, this statistical technique is well suited to the current data structure. A mixed model is able to describe the underlying trends of a particular component in the population (fixed part), and also models the unexplained variation around the mean trend for that component (random part) (Twisk, 2003). 
Each match-running performance characteristic was modelled in turn. Relevant parameters were systematically added to a null model and were accepted or rejected on the basis of changes in model fit as indicated by differences in -2 loglikelihood between models, and the effect of predictor variables on the outcome variable as indicated by z-scores. Firstly, to investigate the variance between players, the intercept was allowed to vary randomly between players. Then the effect of age (centred at 13 years) on the variable was modelled. Quadratic age terms were then modelled. Subsequently, the effect of playing position and being retained or released was modelled. Finally, the effect of the sampling frequency of the GPS unit used was controlled for. Following each analysis, the assumption that variation in intercepts were normally distributed with an average of zero, was checked (Twisk, 2003). Statistical significance was accepted at the 95\% confidence level $(p<0.05)$. Where appropriate, pairwise comparisons between playing positions were conducted to identify where differences occurred. Mean $\pm \mathrm{SD}$ were used to describe the average and variability of data. To calculate the range in which predicted values were likely to fall, 95\% confidence intervals (CI) were reported. Effect sizes (ES) and associated confidence intervals were calculated using the method of Tymms (2004) to assess any meaningful effects, and these were interpreted as small (0.20-0.49), medium (0.50$0.79)$ or large $(>0.80)$ effects (Cohen, 1988).

\section{Results}

Table 3 shows the final mixed models for the development of the match-running performance characteristics of total distance covered, and distance covered at lowspeed, at high-speed, and sprinting, for players of different playing positions and different playing statuses. 
The random part of the mixed models predicted that the fit of all models was improved by allowing the intercepts to vary randomly $(\mathrm{p}<0.05)$, as indicated by the between-player standard deviations displayed in Table 3. From the fixed part of the mixed models, Figures $1 \& 2$ display the predicted age-related changes in matchrunning performance for each playing position. The mean \pm SD match-running performance for each age group is also displayed for each playing position on Figures $1 \& 2$ (see Supplementary table for mean \pm SD match-running performance by age group and positon). Modelling indicated that age-related changes were non-linear; each match-running performance characteristic best described with a quadratic age term $(\mathrm{p}<0.05)$. Models predicted that total distance, low-speed distance, high-speed distance, and sprinting distance all increased with age, but at a constant negative rate, resulting in an eventual plateau and subsequent decrease in total distance, high-speed distance, and sprinting distance with age at 17.7 years, 16.1 years, and 17.3 years, respectively. Conversely, low-speed distance continued to increase throughout the age range without plateau (Figures $1 \& 2$ ).

\section{INSERT TABLE 3 HERE}

\section{INSERT FIGURES $1 \& 2$ HERE}

Modelling predicted that playing position affected the age-related changes of all match-running performance characteristics $(\mathrm{p}<0.05)$ (Table 3). Pairwise comparisons revealed significant differences between most playing positions in match-running performance $(p<0.05)$. However, for total distance there were no significant differences between: $\mathrm{CB}$ vs. FB, CM vs. WM, and CM vs. Multi ( $\mathrm{p}>0.05)$, with $\mathrm{CB}$ completing the least and WM the most, total distance. For low-speed distance there were no significant differences between: $\mathrm{CB}$ vs. $\mathrm{FB}, \mathrm{CB}$ vs. $\mathrm{WM}, \mathrm{CB}$ vs. $\mathrm{CF}, \mathrm{CB}$ vs. 
Multi, FB vs. CF, WM vs. CF, and WM, vs. Multi ( $>>0.05$ ), with FB covering the least and $\mathrm{CM}$ covering the most, low-speed distance. For high-speed distance there were no significant differences between: $\mathrm{CM}$ vs. $\mathrm{CF}, \mathrm{CM}$ vs. Multi, and CF vs. Multi (p>0.05), with CB completing the least and WM the most, high-speed distance. For sprinting distance there were no significant differences between: $\mathrm{CB}$ vs. $\mathrm{CM}$ and $\mathrm{CF}$ vs. Multi ( $>0.05)$, with $\mathrm{CB}$ covering the least and WM covering the most, sprinting distance. When the differences in the distances completed by performers based on their playing position were evaluated, the range of effect sizes (with associated 95\% CI) were: Total distance: $\mathrm{CB}$ vs. WM, $1.6 \pm 0.6$; $\mathrm{CB}$ vs. FB, $0.3 \pm 0.4$; Low-speed distance: FB vs. $\mathrm{CM}, 1.0 \pm 0.4$; FB vs. $\mathrm{CF}, 0.1 \pm 0.4$; Low-speed distance: $\mathrm{CB}$ vs. $\mathrm{WM}, 2.0 \pm 0.6$; CB vs. FB, $0.6 \pm 0.4$; Sprinting distance: $\mathrm{CB}$ vs. $\mathrm{WM}, 1.9 \pm 0.7$; $\mathrm{CB}$ vs. CM, $0.1 \pm 0.5$.

Models predicted that retained players completed significantly more low-speed running compared to released players, $(\mathrm{p}<0.05)$ by $75 \pm 36 \mathrm{~m} \cdot \mathrm{h}^{-1}(95 \% \mathrm{CI}: \pm 71, \mathrm{ES} \pm$ 95\% CI: $0.35 \pm 0.34)$. There were no other significant or meaningful differences between released and retained players in match-running performance $(\mathrm{p}>0.05)$, with effect sizes $( \pm 95 \% \mathrm{CI})$ of $0.14 \pm 0.32,0.10 \pm 0.32$, and $0.08 \pm 0.37$ for total, highspeed, and sprinting distances respectively.

It is possible to calculate the performance of players of differing ages, playing positions and playing statuses using the coefficients from Table 3. For example, the prediction equation for total distance for a 12.2 year-old, wide midfielder, measured with $5 \mathrm{~Hz}$ GPS system who is retained is: Wide midfielder intercept $+\left(\beta_{1}\right.$ *age centred at $13 \mathrm{y})+\left(\beta_{2} *\right.$ age centred at $\left.13 \mathrm{y}^{2}\right)+\left(\beta_{3} * 5 \mathrm{~Hz}\right.$ sampling rate $)+\left(\beta_{4} *\right.$ retained $)$, which 
is: $6510 \mathrm{~m} \cdot \mathrm{h}^{-1}+\left(270 \mathrm{~m} \cdot \mathrm{h}^{-1} *-0.8 \mathrm{y}\right)+\left(-29 \mathrm{~m} \cdot \mathrm{h}^{-1} * 0.64 \mathrm{y}\right)+\left(-296 \mathrm{~m} \cdot \mathrm{h}^{-1}\right)+\left(50 \mathrm{~m} \cdot \mathrm{h}^{-1}\right)=$ $6030 \mathrm{~m} \cdot \mathrm{h}^{-1}$

\section{Discussion}

The aim of the present study was to employ a longitudinal design to examine agerelated changes in the match-running performance of retained and released elite male youth soccer players aged 8-18 years. The mixed models suggested that matchrunning performance characteristics changed with age in a non-linear manner and there was significant variation between players (between-player SD). Modelling also suggested that match-running performance characteristics were influenced by playing position and that retained players covered more low-speed distance compared to released players.

\section{Age-Related Changes}

Predictive modelling suggested that total distance increased with age at a constant negative rate, which resulted in a plateau and subsequent decrease at 17.7 years (Figure 1). Total distance increasing with age and then differences disappearing at older ages is a pattern similar to that seen in previous research (Buchheit et al., 2010; Harley et al., 2010). For example, Buchheit et al. (2010) showed that in U13-U18 elite youth players, when adjusted for match time, U13 players covered significantly less distance than U16-U18 players, but there were no differences in distance covered between any of the older age groups. A combination of growth, training, and tactical factors may account for the pattern of change in distance covered with age.

The increase in distance covered during match-play with age may be due to the improving physiological capacity of players associated with growth and training. 
Indeed, Armstrong and Welshman (1994) indicated that $\dot{\mathrm{VO}}_{2}$ peak $\left(1 \cdot \mathrm{min}^{-1}\right)$ in boys increases linearly from the age of 8 to 16 years of age. Moreover, performance on an intermittent exercise test has been shown to increase with age in elite youth soccer players aged 14-18 years (Roescher et al., 2010), and this improving physiological capacity may allow older players to cover more distance during match-play. The preceding argument is strengthened by studies showing that intermittent exercise test performance is related to total distance covered during match-play in elite youth players (Castagna et al., 2009). However, for this argument to be valid, it would be expected that the age-related changes in intermittent exercise test performance would mirror the age-related changes in match-running performance, which does not appear to be the case. Indeed, the intermittent exercise test performance of elite youth soccer players increases in a linear manner with age (Roescher et al., 2010), whereas the current study shows that total distance covered during match-play increases at constantly negative rate with eventual plateau at age 17.7 years. Why does matchrunning performance start to decrease at older ages despite intermittent exercise test performance continuing to increase? It is possible that at older ages the technical and tactical aspects of match-play are also changing, meaning that there is not requirement or opportunity for players to perform to their maximal capacity. However, it is also possible that the discrepancy in development between intermittent exercise test performance and match-running performance is due to differences between countries in playing style. Indeed the aforementioned studies involved players from across Europe and it has been shown that different countries display differences in physical and technical performance during match-play, hence possibly modifying the relationship between fitness test performance and match-running performance (Dellal et al., 2011). 
Summation of the low-speed distance curve and high-speed distance curve is approximately equal to the total distance curve (see Figure 1). Therefore, examination of these curves can identify specific patterns of age-related change in distance covered at various speeds. In general terms, as per total distance, there was a trend for an increase in distance covered at varying speeds with age. Also, players completed more low-speed distance relative to high-speed distance. For example, at age 12 years, players were predicted to cover a total distance of $5627-6257 \mathrm{~m}$, of which $24-30 \%$ (1359-1913 m) was at high-speed. Similarly at age 16 years players were predicted to cover a total distance of 6475-7105 m, of which 25-31\% (1651-2205 m) was at highspeeds. Whilst cautioning comparisons between studies applying different speed zones thresholds, Harley et al. (2010) showed 30\% of total distance was covered at high-speed in elite youth players aged U12-U16.

There were different patterns of age-related changes in distance covered at different speeds. Indeed, whereas low-speed distance continued to increase throughout the age range there was a decrease in high-speed distance from age 16.1 years and sprinting distance from age 17.3 years. Age-related changes in distance covered at given speed zones are age group specific. Therefore at older ages, players are less likely to produce distance at speeds close to their highest capabilities compared to slightly younger players, suggesting that it is high-speed running and sprinting that are especially constrained by the increased tactical demands of match-play at older ages. The pattern of age-related change in high-speed running between players U13-U18 observed in the current study is similar to previous cross-sectional data. MendezVillanueva et al. (2013) used individualised speed thresholds and showed that in the first half of match-play elite youth players aged U13 covered more very high-speed distance compared to U15-U18 players and there were no differences between older 
age groups. However, the current study is the first to provide insight into age-related changes in distances covered at varying speeds during match-play across a wide age range of elite youth players.

\section{Playing Position}

According to the predictive models, playing position influenced total distance and distance covered at varying speed zones. There were significant differences between most playing positions in match-running performance and whilst effect sizes were generally small, clear activity profiles according to positional role emerged and these were similar to those seen in elite youth players (Buchheit et al., 2010) and professional senior players (Di Salvo et al., 2007). Indeed, midfielders covered the most total distance probably due to their linking role between attack and defence within the team (Di Salvo et al., 2007). Whilst wide midfielders covered the most high-speed distance and sprinting distance, centre midfielders covered the most lowspeed distance. The reason for this may be that due to their central position on the pitch, centre midfielders have less space in which to attain high speeds on a regular basis. Conversely, wide midfielders are often required to produce high-speed runs in order to create goal scoring opportunities. Similarly, centre forwards covered the second most distance sprinting suggesting that very high-speed running is required for tasks such as capitalising on goal scoring opportunities (Faude et al., 2012). Centre backs covered the least total distance, high-speed distance, and sprinting distance, potentially because their major aim is to prevent goals being conceded and so they restrict their movements to certain strategic areas on the pitch (Buchheit et al., 2013). Full back's main duties are defensive, hence these players covered similar total distances to centre backs. However, their wider position means they are less constrained in their movements and can be involved in attacking build-up play and 
this was reflected by them completing more high-speed and sprinting distance compared to centre backs. The current study is the first to assess the positional matchplay demands of elite youth players across an age range that includes both children and adolescents approaching adulthood. That there was an effect of playing position on all match-running performance characteristics suggests that from as young as eight-years-old, elite youth players are able to adjust their match-running performance based upon the tactical requirements of their playing position.

\section{Playing Status}

There was no significant or meaningful difference between released and retained players in total distance covered, which is contrary to previous work showing that U14 elite players cover more distance compared to sub-elite players (Waldron \& Murphy, 2013). However, in support of the current results, Goto et al. (2013) showed that in elite youth players aged U9-U10, there was no difference between released and retained players in distance covered. Taken together, this suggests that in a more homogenous groups of players, total distance covered may not be sensitive enough to differentiate between playing standards. Moreover, there were no differences between released and retained players in high-speed distance and sprinting distance in the current study.

Previous research has suggested that high-speed running is an important aspect of performance as it may aid key activities such as successful attempts at scoring, losing a marker, reaching a ball before an opponent, gaining more time on-the-ball etc (Carling et al., 2008; Faude et al., 2012). Waldron and Murphy (2013) showed some support for this proposition when they revealed U14 elite players covered more highspeed distance $\left(3.64-5.28 \mathrm{~m} \cdot \mathrm{s}^{-1}\right)$ compared to sub-elite players. However, they found 
no difference between groups in very high-speed movement $\left(>5.28 \mathrm{~m} \cdot \mathrm{s}^{-1}\right)$. Therefore it appears that whilst high-speed distance may be moderately effective in discriminating between elite and sub-elite players, when players have already been identified as elite and subjected to systematic talent development programmes, these factors are not sensitive enough to discriminate between players. The previous suggestion is supported by the current study and Goto et al. (2013) who showed no difference in moderate or high-speed running distance between released and retained elite youth players aged U9-U10. That playing status had a limited effect on total, high-speed, and sprinting distances suggests that other factors, such as anthropometric, physiological, psychological, technical, and tactical characteristics may need to be included in future studies of soccer talent. Indeed, Huijgen et al. (2012) recently showed that in 16-18 year-old elite youth soccer players, retained players were discriminated from released players on the basis of a combination of superior sprint speed, dribbling skill, and tactical skill (positioning and deciding). However, it is also possible the $1 \mathrm{~Hz}$ and $5 \mathrm{~Hz}$ GPS sampling rate used in the present study may be too low to capture some of the high-speed movements performed by elite youth soccer players, making it a possible limitation of the study.

In the current study, retained players did cover significantly and meaningfully more low-speed distance compared to released players, which seems rather counterintuitive as it is difficult to see why low-speed activity would influence success. Nevertheless, whilst previous findings are equivocal there is some support for this result. Indeed, Waldron and Murphy (2013) showed elite U14 players covered more low-speed distance $\left(<1.67 \mathrm{~m} \cdot \mathrm{s}^{-1}\right)$ compared to sub-elite players, but this difference did not extend to moderate-speed distance $\left(1.67-3.63 \mathrm{~m} \cdot \mathrm{s}^{-1}\right)$. Goto et al. (2013) showed increased 
low-speed running distance in retained versus released players, but this difference did not extend to walking and jogging.

One possible explanation for low-speed distance differentiating between released and retained players in the current study is that players performing high amounts of lowspeed activity are completing tactically astute movements. This supports the evidence of Huijgen et al. (2012) who showed that in 16-18 year-old elite soccer players, retained players had superior deciding and positioning tactical skills compared to released players. Indeed, retained players constantly adjusting their position at low speeds in relation to the ball, their teammates, and the opposition may result in less need to produce high-intensity bursts to be in an appropriate playing position (Waldron \& Murphy, 2013). There is limited support for this theory at this stage but future research should consider tactical aspects of match-running performance characteristics.

Another reason retained players produced more low-speed distance than released players may relate to the classifications of movement employed in the current study. Low-speed running was defined on the basis of age-group-specific sprint speed, but high intensity actions can occur at low speeds (Stølen et al., 2005). For example, quick accelerations and decelerations, directional changes, jumping actions, and sustaining forceful contractions to maintain balance and control of the ball against defensive pressure, are all high intensity activities that may have been classified as low-speed running in the current study. It is possible that retained players engage in these key activities more frequently and therefore accrue more low-speed distance compared to released players. Future research is required to investigate this phenomenon. 


\section{Random Variation Between Players}

Modelling revealed that there was random variation between players in total distance, low-speed distance, high-speed distance, and sprinting distance that was not explained by age, playing position or playing status. Differences between players in maturity status, physiological training status, match circumstance, and technical and tactical abilities may be responsible for this unexplained variation. For example, previous research into elite youth match-play has shown differences in match-running performance between conventional centre forwards and centre forwards playing slightly behind a strike partner (Buchheit et al., 2010), whereas this distinction was not considered in the current study. Regardless, it is clear that there is variation between successful players in match-running performance characteristics, highlighting the complex nature of match-play in elite youth soccer.

\section{Perspectives}

Results from the current study show that match-running performance characteristics change non-linearly with age and playing position influences development. These findings may allow talent development experts to plan training programmes specific to the demands of match-play at different ages and for different playing positions. This result supports the work of Buchheit et al. (2010) who also showed matchrunning performance changed with age and was highly dependent on playing position in elite youth soccer players aged 12-18 years. However, another key finding in the current study was that there was considerable variation between players in the development of match-running performance characteristics, suggesting a need for flexibility when developing training programmes. Indeed factors such as growth, physiological training status, and technical and tactical abilities probably influence 
match-running performance characteristics and so need to be considered in any talent development programme. Although retained players covered more low-speed distance compared to released players it is not recommended that this be a focus of talent identification procedures. Further study of the actions comprising low-speed running distance in elite youth soccer match-play is warranted in order to better understand factors that differentiate retained and released players.

\section{References}

Armstrong, N, Welshman, J. Assessment and interpretation of aerobic fitness in children and adolescents. Exerc and Sports Sci Rev. 1994: 22: 435-476.

Aslan A, Açıkada C, Güvenç A, Gören H, Hazır T, Özkara A. Metabolic demands of match performance in young soccer players. J Sports Sci Med. 2012: 11: 170179.

Brink MS, Nederhof E, Visscher C, Schmikli, SL, Lemmink, KA. Monitoring load, recovery, and performance in young elite soccer players. J Strength Cond Res. 2010: 24 (3): 597-603.

Buchheit M, Mende-Villanuev A, Simpson BM, Bourdon PC. Match running performance and fitness in youth soccer. Int J Sports Med. 2010: 31: 818-825. Buchheit M, Simpson BM, Mendez-Villanueva A. Repeated high-speed 
activities during youth soccer games in relation to changes in maximal sprinting and aerobic speeds. Int J Sports Med. 2013: 34 (1): 40-48.

Bradley PS, Sheldon W, Wooster B, Olsen P, Boanas P, Krustrup P. High-intensity running in English FA Premier League soccer matches. J Sports Sci. 2009: 27 (2): $159-168$.

Carling C. Influence of opposition team formation on physical and skill-related performance in a professional soccer team. Eur J Sport Sci. 2011: 11 (3): 155164.

Carling C, Bloomfield J, Nelsen L, Reilly T. The role of motion analysis in elite soccer. Sports Med. 2008: 38 (10): 839-862.

Castagna C, Impellizzeri F, Cecchini E, Rampinini E, Barvero-Alvarez JC. Effects of intermittent-endurance fitness on match performance in young male soccer players. J Strength Cond Res. 2009: 23 (7): 1954-1959.

Cohen, J. (1988). Statistical power analysis for the behavioral sciences (2nd edn.). Mahwah, NJ: Lawrence Erlbaum Associates.

Cummins C, Orr R, O’Connor H, West C. Global positioning systems (GPS) and microtechnology sensors in team sports: a systematic review. Sports Med. 2013: 43 (10): 1025-1042.

Dellal A., Chamari K, Wong DP, Ahmaidi S, Keller D, Barros R, ... Carling, C. Comparison of physical and technical performance in European soccer matchplay: FA Premier League and La Liga. Eur J Sport Sci. 2011: 11(1): 51-59.

Di Salvo V, Baron R, Tschan H, Calderon Montero FJ, Bachl N, Pigozzi F. Performance characteristics according to playing position in elite soccer. Int $\mathrm{J}$ Sports Med. 2007: 28 (3): 222-227. 
Faude O, Koch T, Meyer T. Straight sprinting is the most frequent action in goal situations in professional football. J Sports Sci. 2012: 30 (7): 625-631.

Goto H, Morris JG, Nevill ME. Match Analysis of U9 and U10 English Premier League Academy Soccer Players using a Global Positioning System: Relevance for Talent Identification and Development. J Strength Cond Res. [Internet]. 2013 [cited 2013 Oct 20]. [Epub ahead of print]. Available from http://journals.lww.com/nscajscr/Abstract/publishahead/Match_Analysis_of_U9_and_U10_English_Premie r.9772 9.aspx. doi: 10.1519/JSC.0b013e3182a0d751.

Harley JA, Barnes CA, Portas M, et al. Motion analysis of match-play in elite U12 to U16 age-group soccer players. J Sports Sci. 2010: 28 (13): 1391-1397.

Huijgen BCH, Elferink-Gemser MT, Lemmink KAPM, Visscher C. Multidimensional performance characteristics in selected and deselected talented soccer players. Eur J Sport Sci. 2012: 1-9 ifirst, doi: 10.1080/17461391.2012.725102.

Macleod H, Morris JG, Nevill A, Sunderland C. The validity of a non-differential global positioning system for assessing player movement patterns in field hockey. J Sports Sci. 2009: 27 (2): 121-128.

Mendez-Villanueva A, Buchheit M, Simpson BM, Bourdon PC. Match play intensity distribution in youth soccer. Int J Sports Med. 2013: 34 (2): 101-110.

Mohr M, Krustrup P, Bangsbo J. Match performance of high-standard soccer players with special reference to development of fatigue. J Sports Sci. 2003: 21 (7): 519-528.

Pereira Da Silva N, Kirkendall DT, Leite De Barros Neto T. Movement patterns in elite Brazilian youth soccer. J Sports Med Phys Fit. 2007: 47 (3): 270-275. 
Rasbash J, Steele F, Browne WJ, Goldstein H. A User's Guide to MLwiN, v2.10. Centre for Multilevel Modelling, University of Bristol: 2009. p 192.

Roescher CR, Elferink-Gemser MT, Huijgen BC, Visscher C. Soccer endurance development in professionals. Int J Sports Med. 2010: 31, 174-179.

Strøyer J, Hansen L, Klausen K. Physiological profile and activity pattern of young soccer players during match play. Med Sci Sports Exerc. 2004: 36 (1): 168174.

Stølen T, Chamari K, Castagna C, Wisloff U. Physiology of soccer: an update. Sports Med. 2005: 5:501-36.

The Football Association Web site [Internet]. London (UK): The FA Guide to pitch and goalpost dimensions, The Football Association; [cited 2013 Nov 22]. Available from: http://www.thefa.com/GetIntoFootball/parentsandvolunteers/Runningaclub/yo urfacilities/ /media/42E67E5DF06C475C8BE0BED035CD325B.ashx.

Twisk JW. Applied Longitudinal Data Analysis for Epidemiology. A Practical Guide. Cambridge: Cambridge University Press: 2003. p.77- 85.

Tymms, P. (2004). Effect sizes in multilevel models. In: But What Does It All Mean? The Use of Effect Sizes in Educational Research Eds: I. Schagen and Elliot, K. National Foundation for Educational Research. p.55-66.

Waldron M, Murphy A. A comparison of physical abilities and match performance characteristics among elite and subelite under-14 soccer players. Paediatric Exerc Sci. 2013: 25, 423-434. 
1

2

3

4

5

6

7

8

9

10

11

12

13

14

15

16

17

18

19

20

21

22

23

24

25

26

27

28

29

30

31

32

33

34

35

36

37

38

39

40

41

42

43

44

45

46

47

48

49

50

51

52

53

54

55

56

57

58

59

60

Waldron M, Worsfold P, Twist C, Lamb K. Concurrent validity and test-retest reliability of a global positioning system (GPS) and timing gates to assess sprint performance variables. J Sports Sci. $2011: 29$ (15): 1613-1619.

Williams CA, Oliver J, Faulkner J. Seasonal Monitoring of Sprint and Jump Performance in a Soccer Youth Academy. Intl J Sports Phys Perf. 2011: 6: 264-275.

\section{ACKNOWLEDGEMENTS}

Conflict of Interests: None

Funding Sources: None

We would like to thank the academy staff for their support and the players for taking part in the study. 


\section{LIST OF FIGURES:}

Figure 1. Total [T], low-speed [L], and high-speed $[\mathrm{H}]$ distance covered $\left(\mathrm{m} \cdot \mathrm{h}^{-1}\right)$ during match-play in elite youth soccer players aged 8-18 years. Curves are based on predicted growth curves from mixed models of longitudinal data. Points are the based on the 'raw' age group data (mean $\pm \mathrm{SD}$ ). Data are presented by playing position during match-play.

Figure 2. Sprinting distance covered $\left(\mathrm{m} \cdot \mathrm{h}^{-1}\right)$ during match-play in elite youth soccer players aged 8-18 years. Curves are based on predicted growth curves from mixed models of longitudinal data. Points are the based on the 'raw' age group data (mean \pm $\mathrm{SD})$. Data are presented by playing position during match-play. 

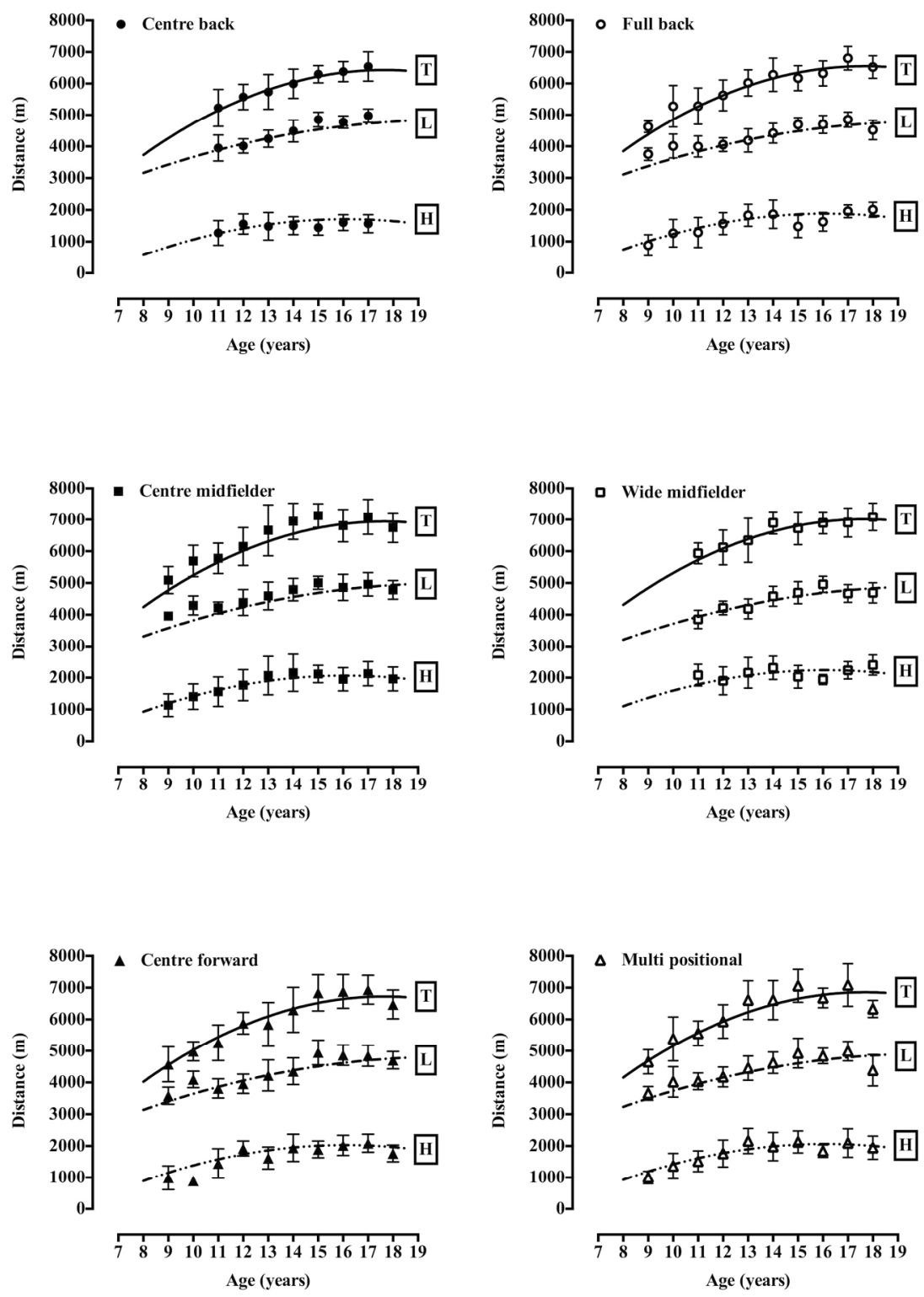

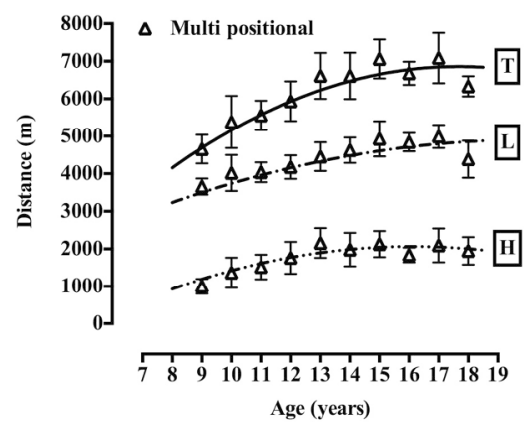

Figure 1. Total $[\mathrm{T}]$, low-speed [L], and high-speed $[\mathrm{H}]$ distance covered (m.h-1) during match-play in elite youth soccer players age 8-18 years. Curves are based on predicted growth curves from mixed models of longitudinal data. Points are the based on the 'raw' age group data (mean \pm SD). Data are presented by playing position during match-play. $165 \times 233 \mathrm{~mm}(300 \times 300 \mathrm{DPI})$ 

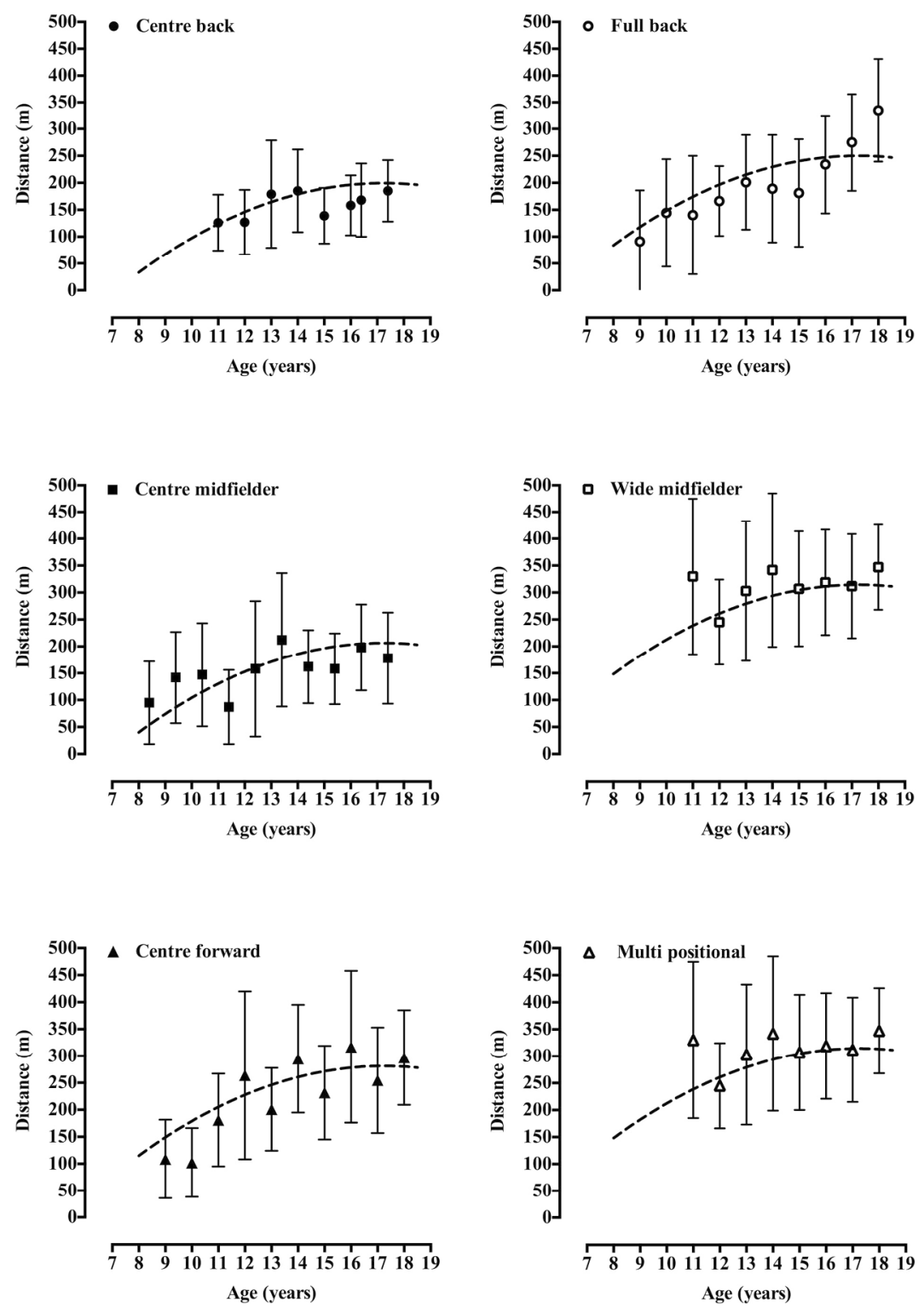

Figure 2. Sprinting distance covered (m.h-1) during match-play in elite youth soccer players age 8-18 years. Curves are based on predicted growth curves from mixed models of longitudinal data. Points are the based on the 'raw' age group data (mean $\pm \mathrm{SD}$ ). Data are presented by playing position during match-play. $166 \times 238 \mathrm{~mm}(300 \times 300 \mathrm{DPI})$ 
Table 1. Basic characteristics of elite youth football players according to age

\begin{tabular}{cccc}
\hline Age Group & Age $(\mathrm{y})$ & Height $(\mathrm{cm})$ & Mass $(\mathrm{kg})$ \\
\hline U9 & $9.2 \pm 0.3$ & $137.6 \pm 5.4$ & $31.4 \pm 5.0$ \\
$\mathrm{U} 10$ & $10.2 \pm 0.3$ & $142.8 \pm 5.6$ & $35.5 \pm 6.7$ \\
$\mathrm{U} 11$ & $11.1 \pm 0.3$ & $146.9 \pm 4.9$ & $38.1 \pm 4.8$ \\
$\mathrm{U} 12$ & $12.2 \pm 0.3$ & $154.0 \pm 7.2$ & $42.8 \pm 6.6$ \\
$\mathrm{U} 13$ & $13.1 \pm 0.3$ & $161.9 \pm 9.4$ & $49.8 \pm 9.3$ \\
$\mathrm{U} 14$ & $14.1 \pm 0.3$ & $170.7 \pm 6.8$ & $59.1 \pm 8.5$ \\
$\mathrm{U} 15$ & $15.0 \pm 0.4$ & $175.7 \pm 6.2$ & $65.8 \pm 7.1$ \\
$\mathrm{U} 16$ & $16.0 \pm 0.4$ & $178.0 \pm 6.4$ & $70.1 \pm 6.5$ \\
$\mathrm{U} 17$ & $17.0 \pm 0.3$ & $178.2 \pm 6.8$ & $73.6 \pm 5.8$ \\
\hline U18 & $18.0 \pm 0.3$ & $179.8 \pm 5.3$ & $73.3 \pm 5.7$ \\
\hline Total & $14.5 \pm 2.6$ & $162.1 \pm 16.0$ & $53.0 \pm 16.1$ \\
\hline Note. Data are displayed as mean $\pm \mathrm{SD}$. & & \\
\hline
\end{tabular}


Table 2. Age group specific speed zone thresholds $\left(\mathrm{m} \cdot \mathrm{s}^{-1}\right)$ as a percentage of mean peak 10$20 \mathrm{~m}$ flying speed

\begin{tabular}{|c|c|c|c|c|}
\hline Age Group & $\begin{array}{l}\text { Low-speed } \\
\text { Zone } \\
(<45 \%)\end{array}$ & $\begin{array}{l}\text { High-speed } \\
\text { Zone } \\
(\geq 45 \%)\end{array}$ & $\begin{array}{l}\text { Sprinting Zone } \\
(\geq 75 \%)\end{array}$ & $\begin{array}{l}\text { Mean } \pm \text { SD } \\
\text { Peak 10-20 m } \\
\text { Flying Speed }\end{array}$ \\
\hline U9 & $<2.74$ & $\geq 2.74$ & $\geq 4.56$ & $6.08 \pm 0.32$ \\
\hline U10 & $<2.84$ & $\geq 2.84$ & $\geq 4.73$ & $6.31 \pm 0.34$ \\
\hline U11 & $<2.91$ & $\geq 2.91$ & $\geq 4.85$ & $6.47 \pm 0.35$ \\
\hline U12 & $<3.05$ & $\geq 3.05$ & $\geq 5.08$ & $6.78 \pm 0.38$ \\
\hline U13 & $<3.19$ & $\geq 3.19$ & $\geq 5.31$ & $7.08 \pm 0.45$ \\
\hline U14 & $<3.34$ & $\geq 3.34$ & $\geq 5.6$ & $7.42 \pm 0.41$ \\
\hline U15 & $<3.49$ & $\geq 3.49$ & $\geq 5.81$ & $7.75 \pm 0.33$ \\
\hline U16 & $<3.51$ & $\geq 3.51$ & $\geq 5.85$ & $7.81 \pm 0.36$ \\
\hline U17 & $<3.59$ & $\geq 3.59$ & $\geq 5.98$ & $7.97 \pm 0.27$ \\
\hline U18 & $<3.59$ & $\geq 3.59$ & $\geq 5.98$ & $7.97 \pm 0.36$ \\
\hline
\end{tabular}


Table 3. Mixed models for the longitudinal development of match-running performance characteristics.

\begin{tabular}{|c|c|c|c|c|}
\hline \multirow[t]{2}{*}{ Parameter } & $\begin{array}{l}\text { Total Distance } \\
\quad\left(\mathrm{m} \cdot \mathrm{h}^{-1}\right)\end{array}$ & $\begin{array}{c}\text { Low-Speed } \\
\text { Distance } \\
\left(\mathrm{m} \cdot \mathrm{h}^{-1}\right)\end{array}$ & $\begin{array}{c}\text { High-Speed } \\
\text { Distance } \\
\left(\mathrm{m} \cdot \mathrm{h}^{-1}\right)\end{array}$ & $\begin{array}{c}\text { Sprinting } \\
\text { Distance } \\
\left(\mathrm{m} \cdot \mathrm{h}^{-1}\right)\end{array}$ \\
\hline & Estimate \pm CI & Estimate \pm CI & Estimate $\pm \mathrm{CI}$ & Estimate \pm CI \\
\hline Centre back & $5930 \pm 140^{\text {cdef }}$ & $4417 \pm 86^{\mathrm{c}}$ & $1510 \pm 100^{\text {bcdef }}$ & $160 \pm 25^{\text {bdef }}$ \\
\hline Full back & $6040 \pm 120^{\text {cdef }}$ & $4364 \pm 73^{\mathrm{cdf}}$ & $1680 \pm 86^{\text {acdef }}$ & $211 \pm 22^{\text {acdef }}$ \\
\hline Centre midfield & $6440 \pm 120^{\text {abe }}$ & $4570 \pm 76^{\text {abdef }}$ & $1866 \pm 90^{\mathrm{abd}}$ & $167 \pm 24^{\text {bdef }}$ \\
\hline Wide midfield & $6510 \pm 130^{\text {abef }}$ & $4466 \pm 80^{\mathrm{bc}}$ & $2039 \pm 94^{\text {abcef }}$ & $275 \pm 25^{\text {abcef }}$ \\
\hline Centre forward & $6220 \pm 130^{\mathrm{abcdf}}$ & $4391 \pm 80^{\mathrm{cf}}$ & $1828 \pm 94^{\mathrm{abd}}$ & $242 \pm 24^{\mathrm{abcd}}$ \\
\hline Multi positional & $6350 \pm 110^{\text {abde }}$ & $4488 \pm 71^{\text {bce }}$ & $1865 \pm 82^{\mathrm{abd}}$ & $240 \pm 22^{\mathrm{abcd}}$ \\
\hline Age & $270 \pm 24$ & $162 \pm 16$ & $108 \pm 18$ & $17 \pm 4$ \\
\hline $\mathrm{Age}^{2}$ & $-29 \pm 6$ & $-11 \pm 4$ & $-17 \pm 4$ & $-2 \pm 1$ \\
\hline GPS rate & $-296 \pm 67 *$ & $-392 \pm 43^{*}$ & $96 \pm 49 *$ & $13 \pm 14$ \\
\hline Status & $50 \pm 110$ & $75 \pm 71 *$ & $-27 \pm 84$ & $-5 \pm 21$ \\
\hline \multicolumn{5}{|l|}{ Random Effects } \\
\hline Between-player SD & $350 \pm 250$ & $220 \pm 160$ & $270 \pm 190$ & $60 \pm 45$ \\
\hline Within-player SD & $380 \pm 170$ & $240 \pm 110$ & $280 \pm 120$ & $80 \pm 36$ \\
\hline
\end{tabular}


Supplementary Table. Match-running performance characteristics by age group and position

\begin{tabular}{|c|c|c|c|c|c|c|}
\hline $\begin{array}{l}\text { Age } \\
\text { Group }\end{array}$ & $\begin{array}{l}\text { Positio } \\
\text { n }\end{array}$ & $\mathrm{N}$ & $\begin{array}{l}\text { Total Distance } \\
\left(\mathrm{m} \cdot \mathrm{h}^{-1}\right)\end{array}$ & $\begin{array}{c}\text { Low-speed } \\
\text { Distance } \\
\left(\mathrm{m} \cdot \mathrm{h}^{-1}\right)\end{array}$ & $\begin{array}{c}\text { High-speed } \\
\text { Distance }\left(\mathrm{m} \cdot \mathrm{h}^{-1}\right)\end{array}$ & $\begin{array}{c}\text { Sprint } \\
\text { Distance } \\
\left(\mathrm{m} \cdot \mathrm{h}^{-1}\right)\end{array}$ \\
\hline \multirow[t]{5}{*}{ U9 } & FB & 5 & $4620 \pm 180$ & $3750 \pm 200$ & $880 \pm 340$ & $91 \pm 95$ \\
\hline & $\mathrm{CM}$ & 6 & $5090 \pm 430$ & $3960 \pm 120$ & $1130 \pm 360$ & $95 \pm 77$ \\
\hline & $\mathrm{CF}$ & 4 & $4580 \pm 560$ & $3590 \pm 270$ & $990 \pm 380$ & $109 \pm 73$ \\
\hline & Multi & 8 & $4660 \pm 380$ & $3660 \pm 220$ & $1000 \pm 200$ & $100 \pm 56$ \\
\hline & Total & 23 & $4750 \pm 430$ & $3740 \pm 240$ & $1010 \pm 300$ & $98 \pm 69$ \\
\hline \multirow[t]{5}{*}{ U10 } & $\mathrm{FB}$ & 9 & $5280 \pm 660$ & $4010 \pm 380$ & $1260 \pm 440$ & $140 \pm 100$ \\
\hline & $\mathrm{CM}$ & 8 & $5700 \pm 490$ & $4290 \pm 300$ & $1400 \pm 400$ & $142 \pm 85$ \\
\hline & $\mathrm{CF}$ & 3 & $4990 \pm 300$ & $4100 \pm 260$ & $895 \pm 42$ & $102 \pm 64$ \\
\hline & Multi & 41 & $5380 \pm 700$ & $4020 \pm 480$ & $1360 \pm 400$ & $170 \pm 100$ \\
\hline & Total & 61 & $5390 \pm 660$ & $4060 \pm 440$ & $1330 \pm 400$ & $156 \pm 99$ \\
\hline \multirow[t]{7}{*}{ U11 } & FB & 17 & $5280 \pm 580$ & $3990 \pm 340$ & $1280 \pm 480$ & $140 \pm 110$ \\
\hline & $\mathrm{CB}$ & 5 & $5230 \pm 590$ & $3950 \pm 410$ & $1280 \pm 390$ & $126 \pm 52$ \\
\hline & $\mathrm{CM}$ & 15 & $5780 \pm 480$ & $4220 \pm 190$ & $1560 \pm 470$ & $147 \pm 96$ \\
\hline & WM & 9 & $5940 \pm 330$ & $3850 \pm 290$ & $2080 \pm 340$ & $330 \pm 150$ \\
\hline & $\mathrm{CF}$ & 11 & $5260 \pm 570$ & $3810 \pm 310$ & $1450 \pm 470$ & $181 \pm 86$ \\
\hline & Multi & 27 & $5560 \pm 390$ & $4040 \pm 270$ & $1520 \pm 330$ & $175 \pm 92$ \\
\hline & Total & 84 & $5520 \pm 520$ & $4010 \pm 310$ & $1520 \pm 460$ & $180 \pm 110$ \\
\hline \multirow[t]{7}{*}{ U12 } & FB & 15 & $5620 \pm 490$ & $4050 \pm 220$ & $1570 \pm 350$ & $166 \pm 65$ \\
\hline & $\mathrm{CB}$ & 16 & $5580 \pm 400$ & $4010 \pm 230$ & $1560 \pm 320$ & $127 \pm 60$ \\
\hline & $\mathrm{CM}$ & 14 & $6150 \pm 600$ & $4390 \pm 410$ & $1760 \pm 490$ & $87 \pm 69$ \\
\hline & WM & 11 & $6120 \pm 550$ & $4220 \pm 220$ & $1900 \pm 440$ & $245 \pm 79$ \\
\hline & $\mathrm{CF}$ & 13 & $5880 \pm 340$ & $3960 \pm 310$ & $1920 \pm 240$ & $260 \pm 160$ \\
\hline & Multi & 21 & $5940 \pm 530$ & $4170 \pm 320$ & $1760 \pm 430$ & $240 \pm 130$ \\
\hline & Total & 90 & $5870 \pm 530$ & $4130 \pm 320$ & $1730 \pm 400$ & $190 \pm 120$ \\
\hline \multirow[t]{7}{*}{ U13 } & FB & 22 & $6020 \pm 420$ & $4190 \pm 370$ & $1830 \pm 350$ & $201 \pm 88$ \\
\hline & $\mathrm{CB}$ & 23 & $5730 \pm 560$ & $4240 \pm 270$ & $1490 \pm 440$ & $180 \pm 100$ \\
\hline & $\mathrm{CM}$ & 16 & $6660 \pm 810$ & $4590 \pm 440$ & $2070 \pm 610$ & $160 \pm 130$ \\
\hline & WM & 16 & $6350 \pm 700$ & $4190 \pm 310$ & $2160 \pm 490$ & $300 \pm 130$ \\
\hline & $\mathrm{CF}$ & 14 & $5840 \pm 690$ & $4220 \pm 490$ & $1620 \pm 350$ & $201 \pm 77$ \\
\hline & Multi & 26 & $6610 \pm 610$ & $4450 \pm 380$ & $2160 \pm 400$ & $290 \pm 140$ \\
\hline & Total & 117 & $6210 \pm 710$ & $4320 \pm 400$ & $1890 \pm 510$ & $230 \pm 120$ \\
\hline \multirow[t]{7}{*}{ U14 } & FB & 24 & $6280 \pm 530$ & $4410 \pm 320$ & $1860 \pm 450$ & $190 \pm 100$ \\
\hline & $\mathrm{CB}$ & 22 & $6000 \pm 470$ & $4490 \pm 350$ & $1510 \pm 290$ & $185 \pm 77$ \\
\hline & $\mathrm{CM}$ & 29 & $6950 \pm 570$ & $4790 \pm 350$ & $2160 \pm 590$ & $210 \pm 120$ \\
\hline & WM & 18 & $6900 \pm 350$ & $4580 \pm 310$ & $2320 \pm 370$ & $340 \pm 140$ \\
\hline & $\mathrm{CF}$ & 19 & $6300 \pm 710$ & $4360 \pm 420$ & $1940 \pm 430$ & $300 \pm 100$ \\
\hline & Multi & 20 & $6610 \pm 620$ & $4630 \pm 340$ & $1980 \pm 450$ & $250 \pm 110$ \\
\hline & Total & 132 & $6520 \pm 650$ & $4560 \pm 380$ & $1960 \pm 510$ & $240 \pm 120$ \\
\hline
\end{tabular}


Supplementary Table cont.

\begin{tabular}{|c|c|c|c|c|c|c|}
\hline $\begin{array}{l}\text { Age } \\
\text { Group }\end{array}$ & Position & $\mathrm{N}$ & $\begin{array}{l}\text { Total Distance } \\
\qquad\left(\mathrm{m} \cdot \mathrm{h}^{-1}\right)\end{array}$ & $\begin{array}{c}\text { Low-speed } \\
\text { Distance } \\
\left(\mathrm{m} \cdot \mathrm{h}^{-1}\right)\end{array}$ & $\begin{array}{c}\text { High-speed } \\
\text { Distance }\left(\mathrm{m} \cdot \mathrm{h}^{-1}\right)\end{array}$ & $\begin{array}{c}\text { Sprint } \\
\text { Distance } \\
\left(\mathrm{m} \cdot \mathrm{h}^{-1}\right)\end{array}$ \\
\hline \multirow[t]{7}{*}{ U15 } & FB & 11 & $6170 \pm 400$ & $4690 \pm 220$ & $1480 \pm 360$ & $180 \pm 100$ \\
\hline & $\mathrm{CB}$ & 15 & $6300 \pm 280$ & $4850 \pm 240$ & $1450 \pm 240$ & $139 \pm 52$ \\
\hline & $\mathrm{CM}$ & 15 & $7130 \pm 380$ & $5010 \pm 210$ & $2120 \pm 280$ & $162 \pm 68$ \\
\hline & WM & 11 & $6730 \pm 520$ & $4700 \pm 350$ & $2030 \pm 360$ & $310 \pm 110$ \\
\hline & $\mathrm{CF}$ & 17 & $6840 \pm 570$ & $4950 \pm 390$ & $1890 \pm 270$ & $232 \pm 87$ \\
\hline & Multi & 10 & $7060 \pm 520$ & $4930 \pm 470$ & $2130 \pm 350$ & $290 \pm 140$ \\
\hline & Total & 79 & $6710 \pm 570$ & $4870 \pm 330$ & $1840 \pm 410$ & $210 \pm 110$ \\
\hline \multirow[t]{7}{*}{ U16 } & FB & 31 & $6320 \pm 400$ & $4700 \pm 280$ & $1630 \pm 300$ & $234 \pm 91$ \\
\hline & $\mathrm{CB}$ & 31 & $6380 \pm 320$ & $4770 \pm 200$ & $1610 \pm 250$ & $158 \pm 56$ \\
\hline & $\mathrm{CM}$ & 25 & $6810 \pm 520$ & $4860 \pm 410$ & $1950 \pm 370$ & $158 \pm 66$ \\
\hline & WM & 18 & $6700 \pm 350$ & $4960 \pm 260$ & $1940 \pm 160$ & $319 \pm 98$ \\
\hline & $\mathrm{CF}$ & 21 & $6890 \pm 540$ & $4870 \pm 330$ & $2020 \pm 320$ & $320 \pm 140$ \\
\hline & Multi & 12 & $6680 \pm 310$ & $4840 \pm 250$ & $1840 \pm 200$ & $259 \pm 71$ \\
\hline & Total & 138 & $6620 \pm 480$ & $4820 \pm 300$ & $1800 \pm 330$ & $230 \pm 110$ \\
\hline \multirow[t]{7}{*}{ U17 } & FB & 13 & $6800 \pm 370$ & $4850 \pm 240$ & $1960 \pm 200$ & $275 \pm 90$ \\
\hline & $\mathrm{CB}$ & 10 & $6540 \pm 470$ & $4970 \pm 220$ & $1570 \pm 290$ & $168 \pm 68$ \\
\hline & $\mathrm{CM}$ & 12 & $7090 \pm 560$ & $4960 \pm 370$ & $2130 \pm 380$ & $198 \pm 80$ \\
\hline & WM & 35 & $6910 \pm 460$ & $4670 \pm 280$ & $2240 \pm 270$ & $312 \pm 97$ \\
\hline & $\mathrm{CF}$ & 34 & $6940 \pm 460$ & $4850 \pm 340$ & $2090 \pm 290$ & $255 \pm 98$ \\
\hline & Multi & 8 & $7090 \pm 670$ & $5000 \pm 310$ & $2090 \pm 460$ & $230 \pm 100$ \\
\hline & Total & 112 & $6900 \pm 490$ & $4830 \pm 320$ & $2080 \pm 350$ & $260 \pm 100$ \\
\hline \multirow[t]{7}{*}{ U18 } & FB & 35 & $6520 \pm 360$ & $4520 \pm 310$ & $2000 \pm 240$ & $335 \pm 96$ \\
\hline & $\mathrm{CB}$ & 32 & $6470 \pm 350$ & $4800 \pm 290$ & $1670 \pm 250$ & $185 \pm 57$ \\
\hline & $\mathrm{CM}$ & 37 & $6750 \pm 480$ & $4780 \pm 290$ & $1960 \pm 380$ & $178 \pm 85$ \\
\hline & WM & 23 & $7090 \pm 440$ & $4690 \pm 320$ & $2400 \pm 320$ & $347 \pm 79$ \\
\hline & $\mathrm{CF}$ & 18 & $6470 \pm 450$ & $4710 \pm 270$ & $1770 \pm 270$ & $297 \pm 88$ \\
\hline & Multi & 5 & $6330 \pm 270$ & $4390 \pm 500$ & $1950 \pm 370$ & $233 \pm 70$ \\
\hline & Total & 150 & $6640 \pm 460$ & $4690 \pm 320$ & $1950 \pm 380$ & $260 \pm 110$ \\
\hline \multirow[t]{7}{*}{ Total } & FB & 182 & $6090 \pm 670$ & $4400 \pm 420$ & $1690 \pm 440$ & $220 \pm 110$ \\
\hline & $\mathrm{CB}$ & 155 & $6130 \pm 550$ & $4580 \pm 410$ & $1560 \pm 310$ & $166 \pm 70$ \\
\hline & $\mathrm{CM}$ & 178 & $6610 \pm 740$ & $4680 \pm 430$ & $1930 \pm 510$ & $165 \pm 97$ \\
\hline & WM & 141 & $6740 \pm 580$ & $4560 \pm 410$ & $2180 \pm 370$ & $320 \pm 110$ \\
\hline & $\mathrm{CF}$ & 154 & $6380 \pm 820$ & $4530 \pm 530$ & $1850 \pm 420$ & $250 \pm 120$ \\
\hline & Multi & 178 & $6040 \pm 870$ & $4320 \pm 510$ & $1730 \pm 500$ & $220 \pm 120$ \\
\hline & Total & 988 & $6320 \pm 760$ & $4510 \pm 470$ & $1810 \pm 470$ & $220 \pm 120$ \\
\hline
\end{tabular}

Notes: $\mathrm{FB}=$ full back, $\mathrm{CB}=$ centre back, $\mathrm{CM}=$ centre midfielder, $\mathrm{WM}=$ wide midfielder, $\mathrm{CF}=$ centre forward, Multi $=$ multi positional player. Data normalised to one hour of match-play. Data are displayed as mean $\pm \mathrm{SD}$. 